work-family balance self-efficacy among Japanese dual-earner workers with pre-school child(ren).

\section{DEVELOPMENT OF AN ONLINE INTERVENTION TOOL TO PREVENT EXPOSURE TO WORKPLACE BULLYING}

1,2,3 Whitney Van den Brande*, ${ }^{2,4}$ Elfi Baillien, ${ }^{1,3}$ Tinne Vander Elst, ${ }^{3,5}$ Hans De Witte, 1,6 Lode Godderis. 'Knowledge, Information and Research Centre (KIR, IDEWE Group), Leuven, Belgium; ${ }^{2}$ Research Department Work and Organisation Studies (KU Leuven), Brussels, Belgium; ${ }^{3}$ Research Group Work, Organisational and Personnel Psychology (KU Leuven), Leuven, Belgium; ${ }^{4}$ Department of Pyschosocial Sience, University of Bergen, Norway; ${ }^{5}$ Optentia Research Focus Area (North-West University), Vanderbijlpark Campus, South Africa; ${ }^{6}$ Centre for Environment and Health (KU Leuven), Leuven, Belgium

\subsection{6/oemed-2018-ICOHabstracts. 1605}

Introduction Although the negative impact of workplace bullying has been empirically demonstrated, there is little research on preventive interventions regarding workplace bullying. In reply, the aim of this study is to develop an evidence-based online intervention tool to prevent employees from being exposed to workplace bullying. Given the significant role of coping strategies and self-efficacy in becoming a target of bullying, we aim to develop an online intervention that (1) discourages emotion-focused coping strategies, (2) stimulates selfefficacy, and (3) reduces exposure to workplace bullying.

Methods The online intervention was developed in three steps. First, we developed a short questionnaire by means of Confirmatory Factor Analysis based on a respresentative sample of the Belgian working population $(n=1.068)$. Second, we developed a personal stress profile module by means of Relative Operating Characteristic Analysis. Third, we developed exercises inspired by the principles of Cognitive Behavioural Therapy.

Result The tool developed (=StressBalancer) contains three steps:

- StressBarometer is a questionnaire that measures the most relevant work-related stressors (i.e., workload, job insecurity, role conflict and role ambiguity), emotion-focused coping strategies and self-efficacy.

- My Stress Profile (= Feedback) provides feedback on the employees' use of emotion-focused coping strategies, their level of self-efficacy and their level of stressors. The profile reports whether employees score safe (= green zone), problematic (= orange zone) or very problematic (= red zone) on these variables.

- Training contains exercises that aim to discourage emotionfocused coping strategies and aim to stimulate self-efficacy.

Discussion Studies have been set up to evaluate the online intervention tool by means of an experimental cross-over design.

\section{EXAMINING THE RELATIONSHIP BETWEEN DEPRESSION SYMPTOM PROFILES AND WORK PRODUCTIVITY LOSS}

${ }^{1}$ Carolyn S Dewa*, 'Jeffrey S Hoch, ${ }^{3}$ Karen Nieuwenhuijsen, ${ }^{3}$ Judith K Sluiter. ' University of California, Davis, Department of Psychiatry and Behavioural Sciences, Sacramento, US; ${ }^{2}$ University of California, Davis, Department of Public Health Sciences, Sacramento, US; ${ }^{3}$ Colonel Institute of Occupational Health, Academic Medical Centre, University of Amsterdam, the Netherlands

10.1136/oemed-2018-ICOHabstracts. 1606
Introduction Depression is one of the most prevalent mental disorders in the working population. About 10\% of workers currently have at least one mental disorder; approximately $2 \%-7 \%$ of the workforce experiences depression. There is growing awareness of the social and economic costs of depression and its heavy workplace burden. Recognising the heterogeneity of workers' experiences of depression, there have been suggestions to focus interventions on individual depression symptoms and symptom clusters (i.e., profiles) rather than depression severity alone. Our analyses explore the question, 'What is the relationship between depression symptom profiles and work productivity loss?'

Methods These analyses use a population-based sample of 2219 employed adults living in Ontario, Canada. Based on PHQ-8 items, depression symptom profiles were identified using cluster analysis methods. Four work productivity loss dimensions (WPLD) were examined: (1) limitations handling time, (2) physical limitations, (3) mental-interpersonal limitations and (4) output demands limitations from the Work Limitations Questionnaire. Associations between the WPLD and the symptom profiles were examined using multiple linear regression.

Results Depression symptom profile groups differed in the magnitude of productivity losses. The group experiencing the highest severity across all symptoms had 5\%-20\% more work productivity losses in all four WPLD compared to the other groups. The group with the most difficulty concentrating had $4 \%-13 \%$ greater productivity losses related to mental-interpersonal limitations than other groups. This group along with those who experienced disruption in sleep, energy, and appetite had $8 \%-12 \%$ greater productivity losses related to limitations handling time than other groups.

Discussion Our results suggest workers have different experiences of depression. To assist workers with depression to continue being productive, attention should be paid to the combinations of types of difficulties and specific job characteristics. By understanding the specific challenges, work accommodations can be designed to target specific challenges workers face.

\section{THE EFFECTS OF MEASURABLE OUTCOMES ON THE ACTIVITY OF HEALTH AT WORK PREVENTION SERVICES}

J Munoz*. Université de Brest Bretagne Occidentale LABERS EA 3149 France. Jorge. munoz@univ-brest.fr

\subsection{6/oemed-2018-ICOHabstracts. 1607}

Introduction In France, governments have been developing health at work plans since the early 2000s. The agricultural sector is no exception. In order to set up such a plan, the French agricultural health insurance fund (Caisse Nationale de la Mutuelle Sociale Agricole) has developed a range of managerial processes. These include outcomes to be achieved, which are in turn based on measurable indicators. The aim of the study is to assess the impact of these managerial processes on prevention.

Methods This research is based on non-participant observations that have been conducted within 5 health at work prevention services over a period of 10 months. Observations have been complemented by 2 series of interviews that have been conducted within the above mentioned services $(n=34)$ and at national level $(n=3)$. Two analyses of these interviews 
have been carried out. A first analysis has been conducted using Alceste software in order to identify semantic universes. The second analysis was a thematic one. Observations have enabled to relate discourses on the one hand and actual prevention work activities on the other.

Results Effects induced by measurable outcomes cause several types of reactions, among which: the questioning of professional identities, the emergence of local forms of negotiation, internal tensions between the members of health at work services.

Conclusion When intervening in work settings, health prevention professionals used to be very critical of the use of measurable outcomes. The ultimate paradox is that it is now their turn to submit to similar organisational and managerial constraints.

\section{EVALUATION OF AN ONLINE INTERVENTION TOOL TO PREVENT EXPOSURE TO WORKPLACE BULLYING}

\footnotetext{
1,2,3 Whitney Van den Brande ${ }^{*},{ }^{2,4}$ Elfi Baillien, ${ }^{1,3}$ Tinne Vander Elst, ${ }^{3,5} \mathrm{Hans}$ De Witte, 1,6Lode Godderis. 'Knowledge, Information and Research Centre (KIR, IDEWE Group), Leuven, Belgium; ${ }^{2}$ Research Department Work and Organisation Studies (KU Leuven), Brussels, Belgium; ${ }^{3}$ Research Group Work, Organisational and Personnel Psychology (KU Leuven), Leuven,Belgium; ${ }^{4}$ Department of Pyschosocial Sience, University of Bergen, Norway; ${ }^{5}$ Optentia Research Focus Area (North-West University), Vanderbijlpark Campus, South Africa; ${ }^{6}$ Centre for Environment and Health (KU Leuven), Leuven, Belgium
}

\subsection{6/oemed-2018-ICOHabstracts. 1608}

Introduction Researchers have underlined the need to address risk factors for workplace bullying by conducting intervention studies. Given the important role of coping strategies, we developed an online intervention tool to teach employees using efficient coping strategies. In this study, we investigated the impact of this online intervention. We hypothesised that the intervention:

1. decreased emotion-focused coping strategies,

2. stimulated self-efficacy, and

3. reduced exposure to bullying.

Methods Longitudinal data were collected in a cross-over study in which participants were assigned to two experimental groups (group 1 and 2) or a control group (group 3). The participants were contacted three times over a period of eight months (time lag of four months between subsequent measurement points) to complete either an online questionnaire or the online intervention. In group 1, participants participated in the intervention during the first four months, including a premeasurement questionnaire and post-measurements after four and eight months. The second group participated in the intervention after four months, including pre-measurements and post-measurements after eight months. The third group did not receive the intervention and only completed the online questionnaire.

Result MANCOVA analyses and non-parametric tests were performed. Results showed that the mean level of exposure to bullying after completing the intervention was lower in both experimental groups compared to the control group. This may indicate that the intervention had an impact on exposure to bullying. However, within-group analysis revealed no significant decrease in workplace bullying over time within group 2 . Further, the means of emotion-focused coping strategies (i.e., mental and behavioural disengagement) were lower in group 2 in comparison with the control group. This may indicate that the intervention discouraged using emotion-focused coping strategies. No significant differences were found for selfefficacy.

Discussion Future research needs to define contextual factors that are necessary to successfully implement this online intervention.

\section{EVALUATION OF FACILITATORS TRAINING IN IMPROVING THE WORKPLACE ENVIRONMENT USING A PARTICIPATORY APPROACH FOR PRIMARY PREVENTION IN MENTAL HEALTH}

${ }^{1}$ E Yoshikawa*, ${ }^{2} \mathrm{~T}$ Yoshikawa, ${ }^{3} \mathrm{Y}$ Takeuchi, ${ }^{3} \mathrm{Y}$ Sano, ${ }^{1} \mathrm{~A}$ Yuasa, ${ }^{3} \mathrm{~K}$ Kogi. ${ }^{1}$ Japanese Red Cross College of Nursing, Tokyo, Japan; ${ }^{2}$ National Institute of Occupational Safety and Health, Kawasaki, Japan; ${ }^{3}$ The Ohara Memorial Institute for Science of Labour, Tokyo, Japan

\subsection{6/oemed-2018-ICOHabstracts.1609}

Introduction The efficacy of a training program conducted for learning actions taken by facilitators engaged in promoting workplace environment improvements using a participatory approach for primary prevention in mental health was studied. The study was aimed at clarifying the effects of the training program on learning their role in facilitating workplace-level improvement actions.

Methods We conducted a three-and-a-half-hour facilitators training program in Tokyo. The participants included 21 occupational health practitioners. After the training, we distributed a questionnaire (response rate: 95.2\%) and studied the effects of the training program. The average years of experience of the respondents was $11.5 \pm 7.6$ years, and the respondents included six persons who had experience in activities to improve their workplace environment. The relation between the level of understanding of the training contents and the respondents' level of confidence about the learning results was analysed by using a chi-squared test.

Results All the respondents answered that they could understand the significance of improving the workplace environment using a participatory approach as well as the role of a facilitator. They evaluated the content of the training as generally high and agreed with the need for taking action-oriented steps applying participatory methods. Concerning the level of confidence about supporting improvement activities, eight respondents (42\%) replied 'very confident' or 'somewhat confident,' and 11 (58\%) 'somewhat unconfident' or 'not confident at all.' The chi-square test did not reveal any statistically significant difference between groups on either item.

Conclusion The facilitators training in promoting the participants' understanding concerning the significance of improving the workplace environment was confirmed effective by using a participatory approach. It has been suggested that, in order to enable the participants to effectively practice at their workplace what they learned from the training, it is important to provide a thorough follow-up after the training. 2 